\title{
Analysis of Tumor Necrosis Factor Promoter Responses to Ultraviolet Light
}

\author{
Flavia Bazzoni, * Véronique Kruys, ${ }^{\star}$ Alexander Shakhov, ${ }^{\star}$ C. Victor Jongeneel, ${ }^{\star}$ and Bruce Beutler ${ }^{*}$ \\ *Department of Internal Medicine and the Howard Hughes Medical Institute, The University of Texas Southwestern Medical Center, \\ Dallas, Texas 75235-9050; and ${ }^{\ddagger}$ Ludwig Institute for Cancer Research, Lausanne Branch, 1066 Epalinges, Switzerland
}

\begin{abstract}
Ultraviolet (UV) light induces the biosynthesis of chloramphenicol acetyltransferase (CAT) in the skin of mice bearing the $\mathrm{CAT}_{\mathrm{TNF}}$ reporter transgene. Moreover, nuclear run-on assays indicate that UV light induces transcription of the TNF gene in RAW 264.7 macrophages. These observations suggest that the TNF gene (and/or its mRNA product) responds to signals elicited by UV light. To identify transcriptional UV response elements within the TNF promoter, and to determine whether a posttranscriptional response might also exist, a series of reporter constructs using a CAT coding sequence attached to various portions of the TNF promoter and $3^{\prime}$ untranslated region were devised and transfected into several cultured cell lines. All cells tested were found to be UV responsive, and in NIH 3T3 cells, induction was found to depend upon two general regions of the promoter. The more distal region encompassed nucleotides (nt) -1059 through -451 with respect to the cap site, while the more proximal region spanned $\mathrm{nt}-\mathbf{4 0 3}$ through -261. A negative element, blocking the UV response, was interposed ( $n t-451$ through -403 ). As with the response to LPS, the response to UV irradiation appears to involve translational activation in macrophages. However, the $U V$ and LPS signaling pathways have little in common with one another, as indicated by three observations. First, no difference in responsiveness was observed on comparison of TNF gene induction in macrophages derived from $\mathrm{C} 3 \mathrm{H} / \mathrm{HeN}$ as opposed to C3H/HeJ mice. Second, cell fusion studies showed that while the LPS signaling pathway is extinguished by fusion of RAW 264.7 cells with NIH 3 T3 cells, the UV signaling pathway remained intact. Finally, induction did not depend upon the NF$\kappa B$ binding sites that are known to be required for LPS response in macrophages, since mutation of these sites did not impair the UV response. (J. Clin. Invest. 1994. 93:56-62.) Key words: lipopolisaccharide $\cdot$ mouse $\cdot$ signal transduction $\cdot N F-\kappa B \cdot$ transcription
\end{abstract}

\section{Introduction}

Ultraviolet (UV) ${ }^{1}$ light is known to stimulate the release of inflammatory cytokines from keratinocytes, and it is currently

Address correspondence to Dr. Bruce Beutler, Howard Hughes Medical Institute, University of Texas Southwestern Medical Center, 5323 Harry Hines Boulevard, Dallas, TX 75235-9050. V. Kruys's present address is Universite Libre de Bruxelles, Faculte des Sciences, Department de Biologie Moleculaire, Laboratoire de Chimie Biologique, Rue des Chevaux 67, 1640 Rhode-Saint-Genese, Bruxelles, Belgium.

Received for publication 21 April 1993 and in revised form $18 \mathrm{Au}$ gust 1993.

1. Abbreviations used in this paper: nt, nucleotides; UV ultraviolet.

J. Clin. Invest.

(c) The American Society for Clinical Investigation, Inc. 0021-9738/94/01/0056/07 \$2.00

Volume 93, January 1994, 56-62 believed that these cytokines mediate certain of the immunopathologic effects of this form of radiation. For example, TNF may elicit inflammation in the dermis when released in response to UV light, and contact hypersensitivity reactions are thought to depend upon its presence (1).

The nature of the "photoreceptor" that UV light stimulates, leading to the biosynthesis and release of TNF, has never been elucidated. Moreover, the signaling pathway used by UV light has yet to be defined. At the most distal extreme of the pathway (i.e., at the level of the gene), the effects of UV irradiation are similarly unclear. UV-responsive elements have been identified in many genes, including, among others, the c-fos gene $(2,3)$, the long terminal repeats (LTRs) of HIV $(3,4)$, and the metallothionine and collagenase genes (3); however, these sequences have little in common with one another, and no such elements have been sought or identified within the TNF gene. While it is known that LPS stimulates TNF gene transcription in macrophages (at least partly by initiating translocation of $\mathrm{NF}_{-} \mathrm{B}$ B to the nucleus) (5), and releases the translational blockade that restricts TNF biosynthesis (6), the level at which UV light stimulates biosynthesis remains to be established.

While dermal keratinocytes are certainly the cells most likely to encounter UV irradiation, and while they maintain the TNF gene in an accessible form (7), the representation of the TNF-inducing UV signaling pathway in other cell types has not been studied. Irrespective of the accessibility of the TNF gene in these tissues, it would be interesting to know whether UV irradiation of other cell types might bring about conditions favorable to transcription of the TNF gene, and translation of its mRNA product.

We initially examined these issues by measuring the response of a chloramphenicol acetyltransferase (CAT) reporter transgene (bearing a total of $3.2 \mathrm{~kb}$ of DNA sequence derived from the mouse TNF gene) to UV light in vivo. Subsequently, we made use of a series of reporter constructs in which truncated versions of the TNF promoter, or promoters displaying mutations within NF- $\kappa$ B sites (which are known to be essential for the response to LPS), were transfected into cultured cells, including macrophages, immortalized fibroblasts, epithelial carcinoma cells, fibrosarcoma cells, and cells of the PAM-212 keratinocyte line.

\section{Methods}

Cell culture. PAM-212 cells were the kind gift of Dr. Ponciano Cruz (University of Texas Southwestern Medical Center). All of the other cell lines (RAW 264.7 macrophages, and NIH 3T3 cells, L-929 fibrosarcoma cells, and HeLa cells) were obtained from the American Type Culture Collection (Rockville, MD) and maintained through multiple passages in our laboratory. Hybrid cell lines produced by fusing RAW 264.7 macrophages with NIH 3T3 cells were created using polyethylene glycol, as previously described (8). In the studies performed, either the RAW 264.7 cell parent or the NIH 3T3 cell parent contained a CAT reporter construct, cotransfected together with pcDNAneo. The parental cell lacking the reporter was transfected with pSV2 puro. Se- 
lection of hybrid cells was carried out by growing the fused cell population in the presence of both $\mathrm{G} 418(1 \mathrm{mg} / \mathrm{ml})$ and puromycin $(5 \mu \mathrm{g} /$ $\mathrm{ml}$ ). As detailed elsewhere (8) the hybrid cells were pentaploid, suggesting the retention of chromosomes from each of the parental lines. and were immortal.

Reporter constructs. Constructs bearing the TNF promoter, with or without the TNF $3^{\prime}$ UTR, have been used in other studies, and thoroughly described in connection with these $(9,10)$. Other constructs, in which successive deletion of the $5^{\prime}$ end of the TNF promoter region have been introduced, were also described previously $(5,11)$. In some of the constructs, discrete mutations were introduced into the NF- $\kappa \mathrm{B}$ binding sites (5). The sites were mutated individually or collectively. A schematic illustration of all of the reporter constructs is shown in Fig. 1. Construct I of Fig. 1 is identical to the transgene designated $\mathrm{CAT}_{\mathrm{TNF}}$ in previous publications $(12,13)$.

Cell transfection and irradiation. Calcium phosphate precipitates of cesium chloride-purified plasmids were used to transfect each of the cell lines studied in these experiments (14). In permanent transfection studies, cells were cotransfected with pcDNAneo and selected for growth in the presence of $\mathrm{G} 418$ at a concentration of $1 \mathrm{mg} / \mathrm{ml}$. Pooled resistant colonies (a minimum of 50 per construct) were then used in irradiation studies. In transient transfection studies, DNA was first digested with NdeI and SmaI (for NF- $\kappa$ B mutants) or with KpnI and BamHI (for promoter deletion mutants), or with Xhol and SmaI (in the case of the promoterless control) to excise the reporter from the vector, since in control experiments certain vector sequences showed UV-responsive properties. The digested plasmid DNA was then mixed at a 1:10 ratio with herring sperm DNA, and transfected $48 \mathrm{~h}$ before UV irradiation. $6 \mathrm{~h}$ before irradiation, the cells were split into two equal aliquots and replated. Cells were then either irradiated or sham irradiated as a control. UV light was applied at the stated energy level (usually $130 \mathrm{~J} / \mathrm{m}^{2}$ ). UV light was delivered at a rate of $65 \mathrm{~J} / \mathrm{m}^{2}$ per $\mathrm{min}$. To irradiate the cells, monolayers were washed twice with phosphate-buffered saline in 10-cm dishes and then left covered with $2 \mathrm{ml}$ of the same solution during the period of exposure.

CAT assay. Cells were lysed by freezing and thawing $16 \mathrm{~h}$ after irradiation. A total of $2 \times 10^{5}$ (NIH 3T3) or $5 \times 10^{5}$ ( L-929, PAM-212, RAW 264.7 , or HeLa ) permanently transfected cells, or $10^{6}$ transiently transfected cells, were used in each CAT assay. Assays were carried out by the thin layer chromatography method of Gorman et al. (15). CAT activity was quantitated using a phosphorimager.

Reagents. Highly purified salmonella R595 LPS was the kind gift of Dr. Chris Galanos (Max Planck Institute für Immunobiologie, Freiburg, Germany). G418, cell culture medium, and serum were obtained from Gibco Laboratories (Grand Island, New York).

Animals. Transgenic mice, produced using the vector-free linearized construct designated $\mathrm{I}$ in Fig. $1\left(\mathrm{CAT}_{\mathrm{TNF}}\right)$, were produced as described elsewhere (12) and bred to carry the transgene in a homozygous state. They were maintained in the Animal Resource Center of the University of Texas Southwestern Medical Center. Mice were anesthetized with metaphane, shaved, and placed in a prone or supine position for the duration of their exposure to UV light. The animals were killed $6 \mathrm{~h}$ after exposure, regions of exposed, and shielded skin isolated and homogenized in a hand-held, all-glass homogenizer, and CAT assays performed as described above.

$\mathrm{C} 3 \mathrm{H} / \mathrm{HeJ}$ and $\mathrm{C} 3 \mathrm{H} / \mathrm{HeN}$ mice, purchased from The Jackson Laboratory (Bar Harbor, ME) and from Charles River Labs. (Wilmington, MA) respectively, were injected with thioglycollate $4 \mathrm{~d}$ before harvest of peritoneal macrophages (16). $3 \times 10^{6}$ adherent cells were used for studies of responses to LPS and to UV light. LPS or UV were applied to the cultures for $6 \mathrm{~h}$ before harvest and RNA preparation.

RNA blot hybridization. Cytoplasmic RNA was isolated from mouse peritoneal macrophages by the method of Favaloro et al. (17). RNA was denatured using sample buffer that contained $50 \%$ formamide, $6.6 \%$ formaldehyde, $20 \mathrm{mM}$ MOPS, $\mathrm{pH} 7.0,1 \mathrm{mM}$ EDTA, and $5 \mathrm{mM}$ sodium acetate. It was subjected to electrophoresis in $1.2 \%$ agarose containing Tris-acetate/EDTA (TAE) (18). It was then transferred to a nylon membrane by electroblotting in TAE, and fixed to the mem- brane by UV irradiation using a Stratalinker apparatus. The membrane was prehybridized using $50 \%$ formamide, $5 \times$ SSPE, $0.1 \%$ SDS, $5 \times$ Denhardt's solution, and salmon sperm DNA at a concentration of 100 $\mu \mathrm{g} / \mathrm{ml}$. An antisense RNA probe $1.1 \mathrm{~kb}$ in length was transcribed from the mouse TNF cDNA (19). It was allowed to hybridize to the blot for $16 \mathrm{~h}$ at $65^{\circ} \mathrm{C}$ in the same solution that was used for prehybridization. Washing was then carried out at $72^{\circ} \mathrm{C}$, twice in $2 \times$ SSC and twice in $0.1 \times$ SSC, each supplemented with $0.1 \%$ SDS. Each wash was for 30 $\min$.

TNF assay: A variant of the L-929 bioassay, using cycloheximide to enhance cell lysis, was used to determine TNF concentration in macrophage culture medium (20). A standard recombinant preparation of mouse TNF was assayed in parallel for quantitation.

Nuclear run-on assay. RAW 264.7 cells were exposed to LPS, UV light, or left unexposed as a control. $1 \mathrm{~h}$ after the treatment, cells were collected and resuspended in lysis buffer ( $10 \mathrm{mM}$ Tris, $\mathrm{pH} 7.6,10 \mathrm{mM}$ $\mathrm{MgCl}_{2}$, and $1 \% \mathrm{NP}-40$ ). The nuclei were subsequently pelleted, and their integrity was checked using an inverted microscope with Hoffmann optics. The nuclei were then resuspended in a solution of $40 \%$ glycerol, $5 \mathrm{mM}$ Tris, $\mathrm{pH} 8.3,10 \mathrm{mM} \mathrm{MgCl}_{2}$, and $0.1 \mathrm{mM}$ EDTA. Transcription was allowed to continue in the presence of $\alpha-\left[{ }^{32} \mathrm{P}\right] U T P$ $(800 \mathrm{Ci} / \mathrm{mmol})$ for $1 \mathrm{~h}$ at $30^{\circ} \mathrm{C}$. Nuclei were disrupted in $4 \mathrm{M}$ guanidinium thiocyanate. Labeled transcripts were purified over a $\mathrm{CsCl}$ gradient, and $5 \times 10^{6} \mathrm{cpm} / \mathrm{ml}$ was allowed to hybridize $\left(65^{\circ} \mathrm{C}\right.$ for $\left.48 \mathrm{~h}\right)$ with $7.5 \mu \mathrm{g}$ of linear DNA. DNAs consisting of the mouse TNF gene ( $1.687 \mathrm{bp}$ in length cloned into Bluescript $)$, the empty Bluescript vector, the mouse GAPDH cDNA ( 550 bp in length cloned into pGEM4), and the empty pGEM4 vector were immobilized on a nylon membrane. After washing twice in $2 \times$ SSC, $0.1 \%$ SDS and in $0.1 \times$ SSC, $0.1 \%$ SDS, the membrane was exposed to Europium screens and the hybridized label was quantitated using a phosphorimager (Molecular Dynamics, Inc., Sunnyvale, CA).

\section{Results}

Transgenic mice exposed to UV light for a period of $10 \mathrm{~min}$ $\left(650 \mathrm{~J} / \mathrm{m}^{2}\right.$ of exposed skin) were found to have accumulated CAT activity in skin $6 \mathrm{~h}$ after irradiation (Fig. 2). This suggested that sequences flanking the reporter were capable of responding to UV light, and prompted us to determine which cells and sequence elements might be involved.

Initial studies were carried out using PAM- 212 cells, which were permanently or transiently transfected with a CAT reporter (bearing a 1.1-kb TNF promoter and the TNF 3' UTR) and exposed to UV irradiation. A marked, dose-dependent increase in CAT activity was observed after exposure to UV light (Fig. $3 \mathrm{~A}$ ). A maximal response was observed at $130 \mathrm{~J} / \mathrm{m}^{2}$. pSVLCAT was not responsive to induction, suggesting the requirement for specific regulatory sequences within the TNF promoter or untranslated regions. The same degree of induction was observed in permanently transfected cells, and occurred with both a 1.1- and a 2.2-kb version of the TNF promoter (Fig. $3 \mathrm{~B}$ ). It has previously been reported that PAM212 cells accumulate TNF mRNA after exposure to UV light (21). Our own data (not shown) indicate that, with the PAM212 clone in use in our laboratory, the TNF gene is silent to induction by UV light, LPS, or cycloheximide. However, the cells clearly retain a mechanism for UV signal transduction.

Permanently transfected cells of several nonkeratinocyte lines were then examined in order to determine whether the response to UV irradiation was a general one. Although the TNF gene is itself inaccessible in two of the lines tested ( HeLa and NIH 3T3; unpublished observation ), the accessibility of the permanently transfected reporter gene has been documented by observing its activation after cycloheximide treat- 


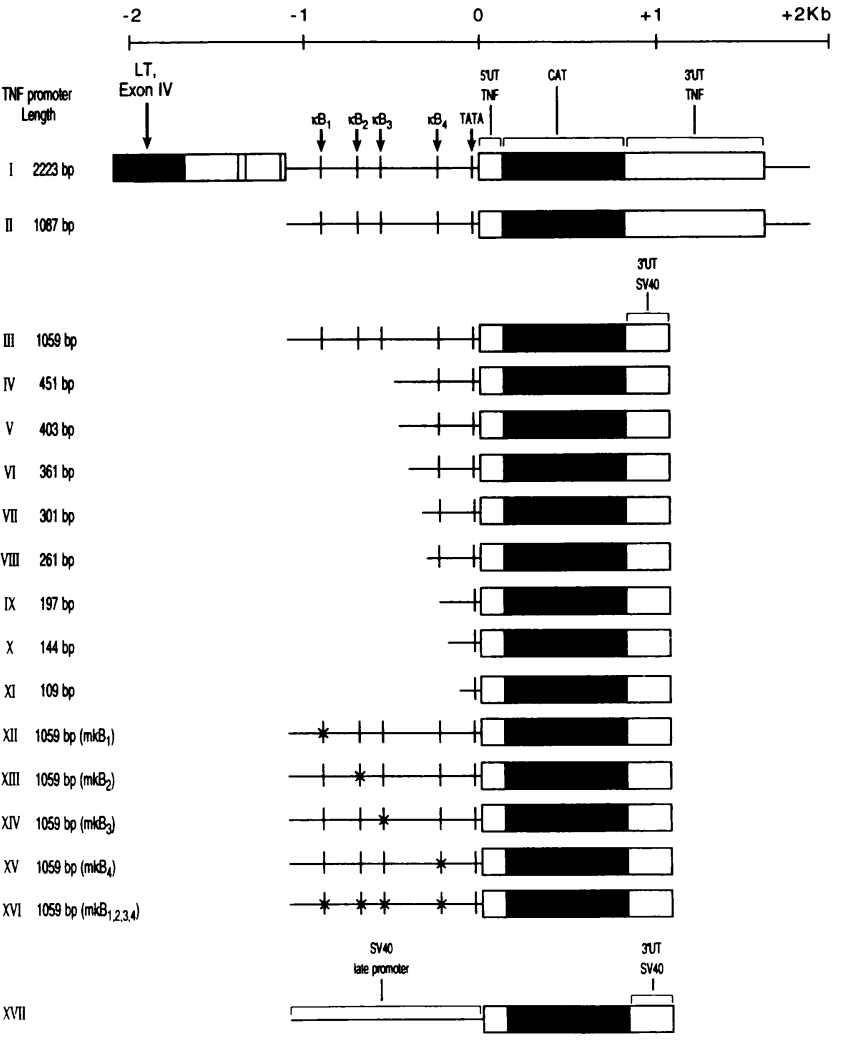

Figure 1. Constructs used in the analysis of UV response. Transcribed sequences are depicted as bars, and the CAT coding sequence is represented by the solid bar. Important landmarks within the promoter are indicated by vertical lines. Numbers refer to the length of TNF promoter sequence upstream from the transcription initiation site. Note that constructs I and II bear TNF 3' UTR and terminator sequences, whereas constructs III-XVI bear SV40 terminator sequences. Construct XVI is transcriptionally driven by the SV40 late promoter rather than the TNF promoter.

ment (8), and it was therefore anticipated that an intact UV signaling pathway would lead to induction of the reporter in any of the cells tested. Indeed, as seen in Fig. 4, all of the lines proved to be responsive. While RAW 264.7 macrophages were more responsive to LPS than to UV irradiation with respect to CAT synthesis, CAT was nonetheless detectable after UV exposure. In L-929 cells, which constitutively express the reporter construct (9), CAT activity was markedly elevated over base-

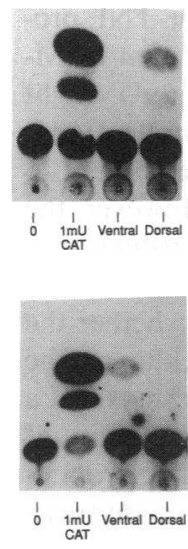

Figure 2. Response of a transgene ( construct I, or $\mathrm{CAT}_{\mathrm{TNF}}$ ) to activation by UV irradiation of the dermis. Mice were irradiated on shaved dorsal or as indicated, administered at a dose of $650 \mathrm{~J} / \mathrm{m}^{2}$. Tissue samples were harvested from both irradiated and nonirradiated areas, and processed as described in Methods. A samUV Irradiation ple containing $100 \mu \mathrm{g}$ of total Ventral Skin system. Controls for CAT assay: no sample added $(0)$, or 1 $\mathrm{mU}$ of CAT added as indicated. ventral surfaces with UV light
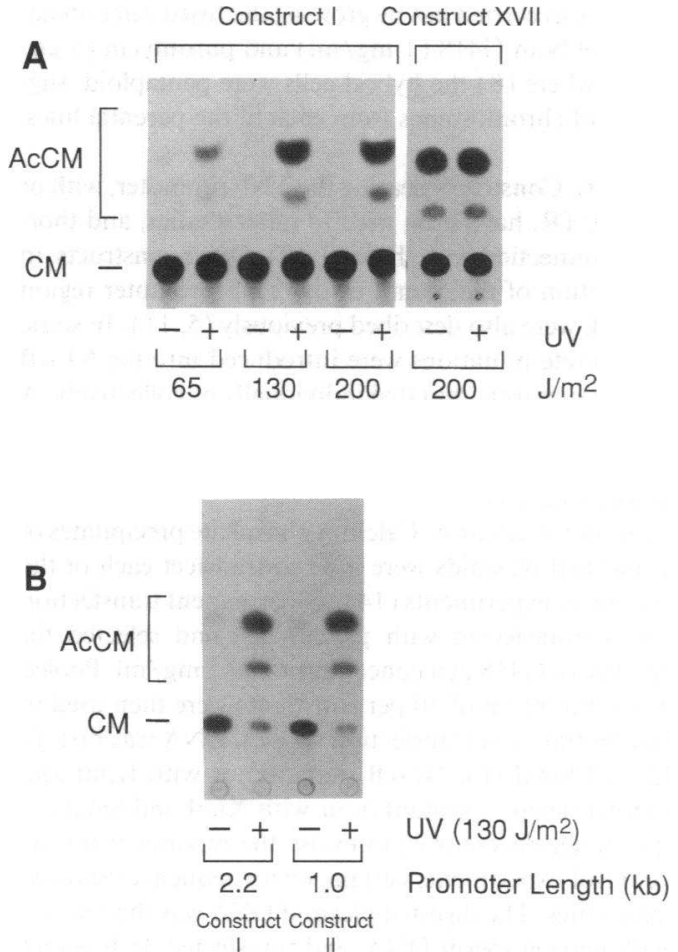

Figure 3. The response of CAT reporter constructs to induction by UV light in PAM-212 cells. ( $A C C M$ ) Acetylated forms of chloramphenicol; $(C M)$ chloramphenicol. Roman numerals refer to construct designations presented in Fig. 1. (+) Irradiated; (-) not irradiated. Cells not subjected to UV irradiation were sham irradiated for a length of time equal to that required to administer the stated dose. $(A)$ Transient transfection. Doses of UV light are indicated along the abscissa. ( $B$ ) Stable transfection. Both a 2.2-kb upstream fragment and a 1.1-kb upstream fragment respond to UV light administered at a fixed dose, with approximately the same induction ratio evident in each case.

line levels after UV irradiation. The strongest response was observed in NIH 3T3 cells.

A series of promoter deletion constructs (Fig. 1; constructs I-IX) was transiently transfected into NIH 3T3 cells. Deletion of the distal half of the promoter, which contains three of the four putative NF- $\mathrm{B}$ binding motifs, led to a complete loss of

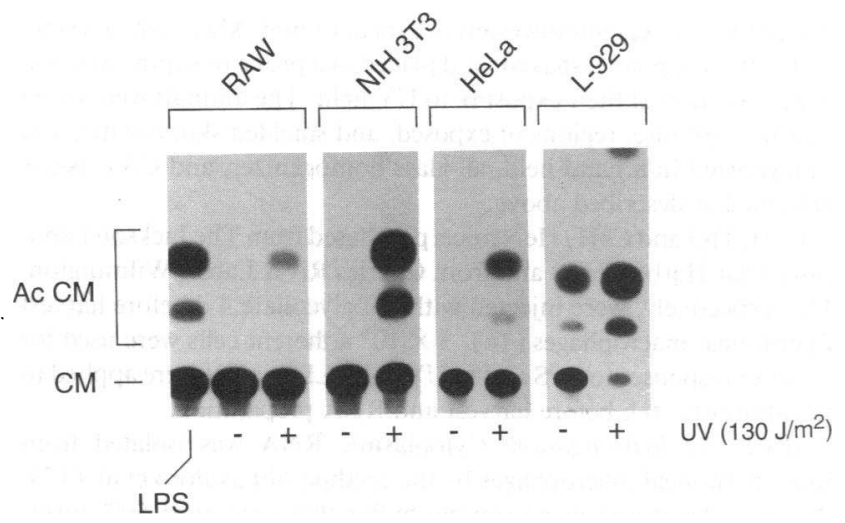

Figure 4. Responses to UV light by different cell lines (RAW 264.7, NIH 3T3, HeLa, and L-929) permanently transfected with construct I (Fig. 1 ). LPS $(1 \mu \mathrm{g} / \mathrm{ml})$, was added to RAW 264.7 cells as a positive control for induction of the reporter. 
A

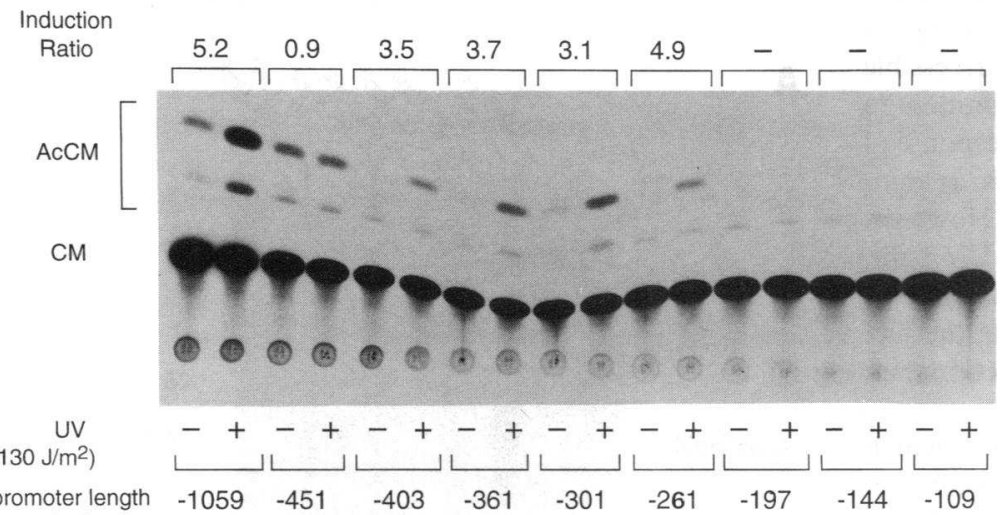

(bp)

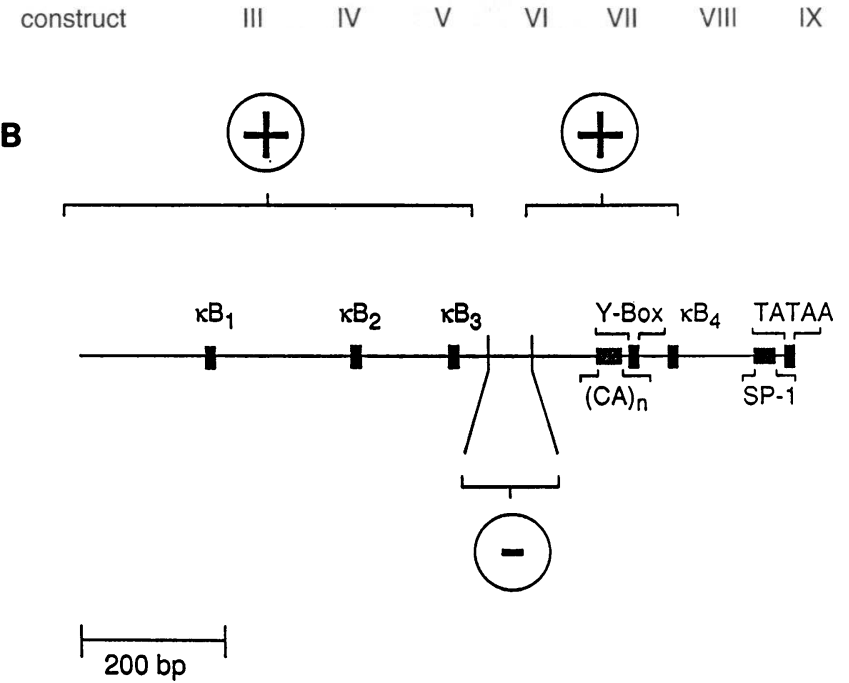

Figure 5. Induction of CAT activity in NIH $3 \mathrm{~T} 3$ cells: effects of promoter deletion. $(A)$ NIH 3T3 cells were transiently transfected with linearized reporter gene fragments containing promoters beginning at the stated position with respect to the point of transcription initiation, as illustrated in Fig. 1. Induction ratio refers to the percentage of chloramphenicol acetylation in induced samples divided by the percentage of chloramphenicol acetylation in noninduced samples, as determined by phosphorimager quantitation. Constructs with promoters beginning at $-197,-144$, and $-109 \mathrm{bp}$ upstream from the cap site yielded no detectable product with or without induction, and hence, no meaningful calculation could be performed $(-)$. (B) Schematic illustration of the effects of promoter deletion. Positive and negative elements are indicated $(+$ and -$)$, referring to the UV response. Other landmarks within the promoter are also indicated.

reporter gene induction by UV irradiation. Interestingly, the further deletion of 47 nucleotides (nt) restored the response, suggesting that a repressive element is interposed between two positively acting elements within the promoter. The response to UV light was maintained through at least two further deletions, spanning an additional $162 \mathrm{bp}$. Further deletions abolished the UV response; however, no basal promoter activity was detectable, indicating that other elements essential for transcription of the linearized reporter fragment might also have been lost: The effects of promoter deletion are illustrated in Fig. 5.

These observations were consistent with the hypothesis that UV-induced TNF gene activation is dependent upon translocation of NF- $\kappa$ B to the nucleus, and its subsequent interaction with the four binding motifs in the promoter region. Surprisingly, however, discrete mutations within the NF- $\mathrm{KB}$ elements, which collectively led to a loss of the response to LPS in macrophages (5), failed to disrupt the response to UV irradiation (Fig. 6).

Recently, it was observed that when NIH 3T3 cells, which maintain the TNF gene in an inactive form and which lack an intact pathway for endotoxin signaling (8), are fused with RAW 264.7 macrophages, genes encoding components of the LPS signaling pathway and the macrophage TNF gene itself are extinguished. To establish whether certain components of the

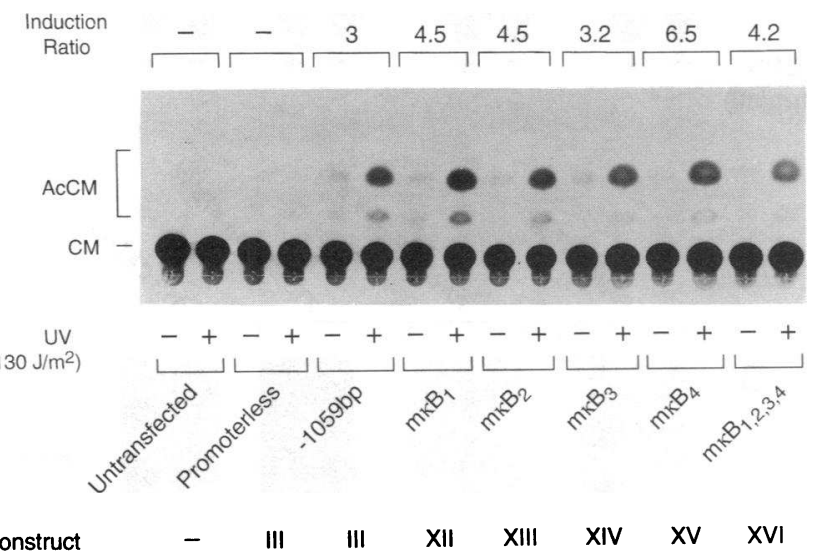

Figure 6. Induction of CAT activity in transiently transfected NIH $3 \mathrm{~T} 3$ cells: effect of mutation of NF- $\mathrm{KB}$ sites within the promoter. A promoterless fragment was generated by digesting DNA derived from construct III (Fig. 1) with Xhol and Smal. Alternatively, fragments with an intact promoter $(-1059)$, or with promoters carrying NF- $\kappa \mathrm{B}$ mutations as indicated, were generated by cleaving the plasmid with NdeI and SmaI (constructs III, XI, XII, XIII, XIV, and XV of Fig. 1). The level of CAT activity in untransfected cells and in cells transfected with promoterless constructs was unmeasurable with the phosphorimager (-). Induction ratio of other transfection assays was calculated as in Fig. 5. 
LPS and UV signaling pathways are shared, we sought to determine whether cell fusion would also extinguish the UV signaling pathway. The reporter gene used becomes less accessible after transfer from the macrophage or 3T3 cell environment to the hybrid cell environment ( 8 ). Therefore, the net response of the reporter to UV light is diminished in hybrid cells, as compared with the response in either parental cell type. However, as illustrated in Fig. 7, hybrid cells did respond to UV light, whereas they failed to respond to LPS (the LPS signaling pathway having been entirely extinguished), this despite the fact that LPS is a stronger stimulus for reporter gene induction than UV light, at least in the macrophage parent cell.

Earlier studies had indicated that $\mathrm{C} 3 \mathrm{H} / \mathrm{HeJ}$ mice, which are genetically unresponsive to LPS, exhibit a defect in response to UV light, insofar as the normal diminution of contact hypersensitivity mediated by UV light does not occur in these animals (22). In an effort to determine whether this defect was manifested at the cellular level in vitro, macrophages were obtained from $\mathrm{C} 3 \mathrm{H} / \mathrm{HeJ}$ and $\mathrm{C} 3 \mathrm{H} / \mathrm{HeN}$ mice, and exposed to UV light. As shown in Fig. 8, no discrepancy was observed between macrophages derived from the two strains in terms of their ability to react to UV light by accumulation of TNF mRNA. It is to be noted that while similar amounts of TNF mRNA are apparent in $\mathrm{C} 3 \mathrm{H} / \mathrm{HeJ}$ macrophages after ex-

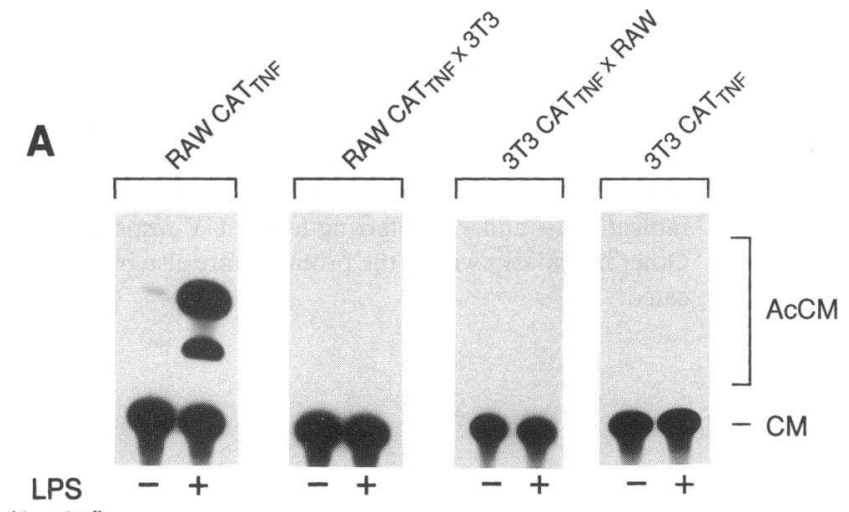

$(1 \mu \mathrm{g} / \mathrm{ml})$

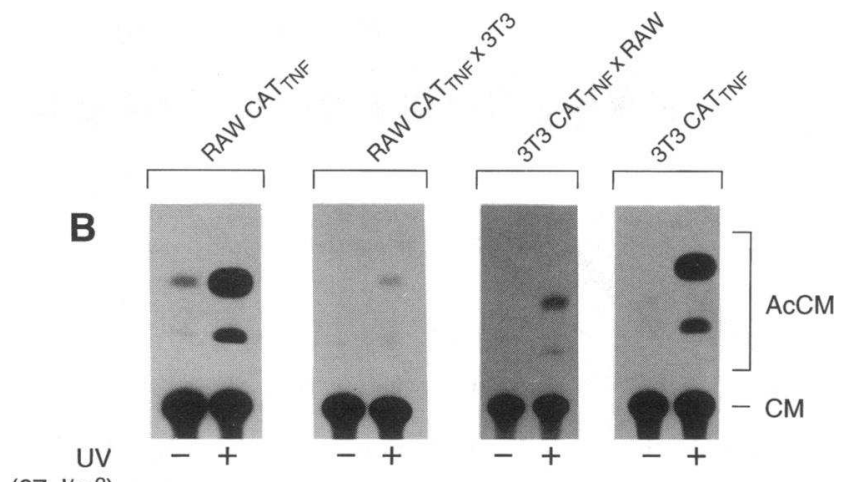

$\left(67 \mathrm{~J} / \mathrm{m}^{2}\right)$

Figure 7. Extinction of the LPS signaling pathway, but not the UV signaling pathway, by somatic cell hybridization. $(A)$ Induction by LPS. ( $B$ ) Induction by UV light. The CAT reporter gene CAT $\mathrm{TNF}_{\mathrm{TNF}}$ (construct 1 of Fig. 1) was present either in the RAW 264.7 cell parent or in the NIH 3T3 cell parent before cell fusion. The other parental cell contained no reporter construct. The reciprocal fusions gave rise either to RAW CAT $\mathrm{TNF}_{\mathrm{TN}} \times 3 \mathrm{~T} 3$ cells or to $3 \mathrm{~T}_{3} \mathrm{CAT}_{\mathrm{TNF}}$ $\times$ RAW cells.

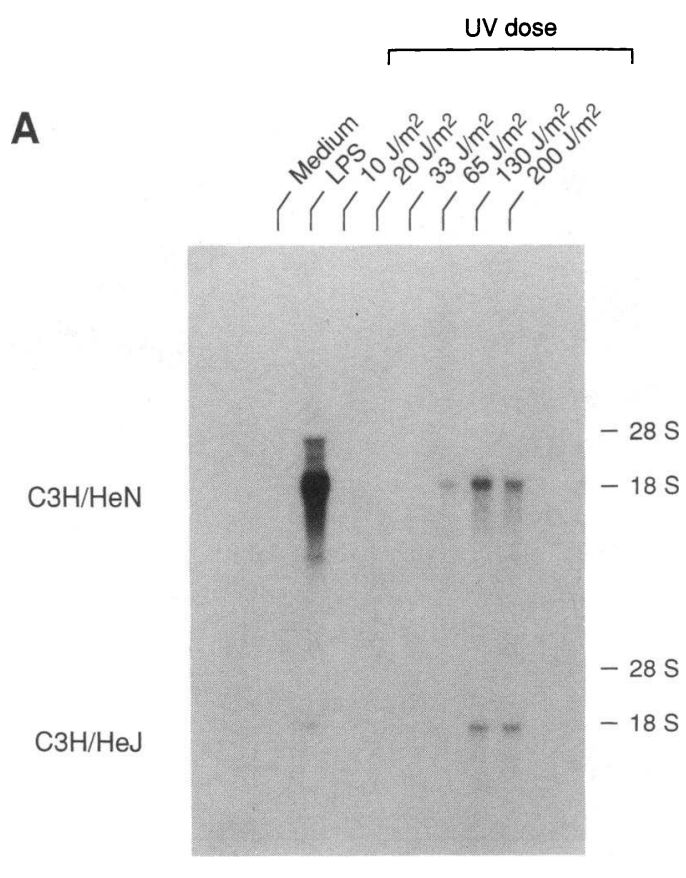

B

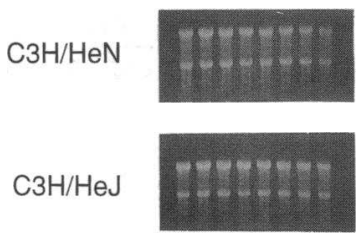

Figure 8. Blot analysis of TNF mRNA expressed in $\mathrm{C} 3 \mathrm{H} / \mathrm{HeN}$ and $\mathrm{C} 3 \mathrm{H} / \mathrm{HeJ}$ macrophages in response to LPS $(5 \mu \mathrm{g} / \mathrm{ml})$ and in response to various doses of UV light. $(A)$ Autoradiogram of blot hybridized to an antisense TNF RNA probe. $(B)$ Photograph of the ethidium-stained agarose gel. $8 \mu \mathrm{g}$ of cytoplasmic RNA was loaded into each lane on the gel. The position of $18 \mathrm{~S}$ and $28 \mathrm{~S}$ ribosomal RNA bands is indicated at the right of the blot.

posure either to LPS or to UV irradiation, only the latter stimulus was capable of eliciting TNF production by these cells (Fig. 9). Thus, the Lps mutation, which impairs responsiveness to endotoxin, seems to have no effect upon cellular sensitivity to UV irradiation. Furthermore, this would suggest that UV irradiation is capable of releasing the translational blockade that is known to impede TNF synthesis in resting macrophages, whereas LPS is incapable of doing so.

In Fig. 8, it is noted that the quantity of TNF mRNA induced by UV light in macrophages from either strain of mouse is very small as compared with the amount of TNF mRNA induced by LPS in the endotoxin-responsive $\mathrm{C} 3 \mathrm{H} / \mathrm{HeN}$ macrophages. While reporter construct studies clearly indicate that elements of the TNF promoter are UV responsive, we wished to document that the authentic TNF gene would also respond to UV irradiation. Knowing that the TNF gene is highly accessible in RAW 264.7 macrophages, we performed nuclear run-on assays using these cells, either untreated, or induced with LPS or with UV light. Since UV light and LPS may each impact upon the transcriptional apparatus in a nonspecific fashion, and may also alter the number of viable cells in the colture, we simultaneously measured transcription from the GAPDH loci, of which $>100$ exist per cell, so as to standardize determina- 


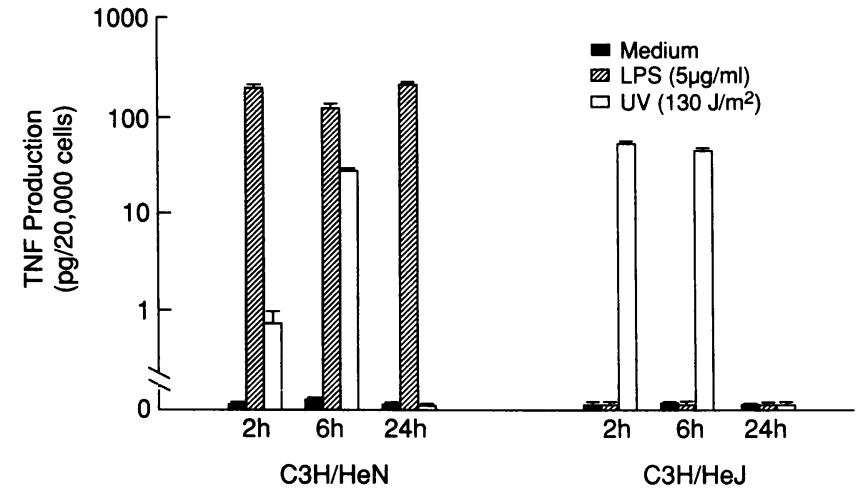

Figure 9. TNF activity in culture medium taken from $\mathrm{C} 3 \mathrm{H} / \mathrm{HeN}$ and $\mathrm{C} 3 \mathrm{H} / \mathrm{HeJ}$ macrophages. Cells of the same culture were used for RNA preparation in Fig. 8. Time points indicated on the abscissa refer to the period elapsed between treatment with UV light or LPS and collection of the medium for assay. Error bars refer to standard deviation of results from four assays performed on each sample. As a control for each time point, macrophages were left untreated (Medium).

tion of TNF gene activity. As illustrated in Fig. 10, UV light causes a relative increase of TNF gene transcription comparable to that elicited by LPS.

\section{Discussion}

The responsiveness of the TNF gene to UV light is demonstrated by the following facts. ( $a$ ) Nuclear run-on assays show a relative increase in the rate of TNF gene transcription after UV irradiation of cells. $(b)$ Primary macrophages accumulate TNF mRNA and secrete active TNF upon exposure to UV light. (c) A reporter transgene bearing TNF promoter and 3' UTR sequences respond to UV light in vivo.

The data we have developed suggest that the TNF gene is responsive to UV light. Only a small segment of the TNF promoter is required for UV response. No more than $261 \mathrm{bp}$ of upstream sequence are sufficient to confer inducibility to the reporter gene. This portion of the promoter contains the TATA and SP1 binding motifs, which commonly reside near the site

Relative

Transcriptional Activity

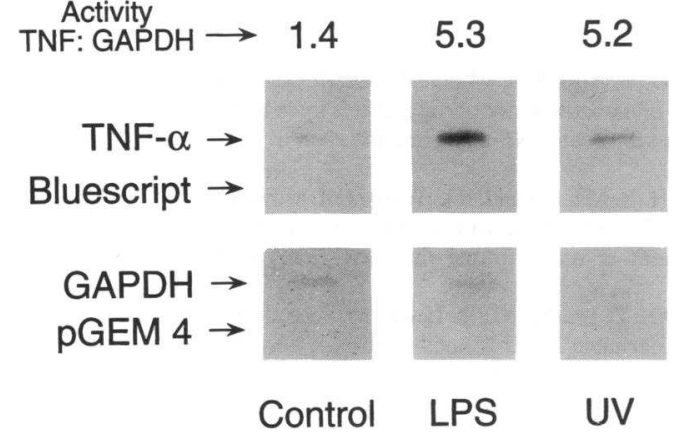

Figure 10. Nuclear run-on assay of TNF and GAPDH gene transcription in RAW 264.7 cells. Cells were left untreated, exposed to LPS, or exposed to UV light as described in the text. Quantitation of signal, by phosphorimager, was used to determine the increase in TNF gene transcription that occurred with each stimulus. The ratio of hybridizing signal $\left(\mathrm{cpm}_{\mathrm{TNF}} / \mathrm{cpm}_{\mathrm{GAPDH}}\right)$ is reported at the top. of transcription initiation, as well as a single NF- $\kappa$ B binding element. Responsiveness persists with the addition of sequences encompassing the well-known Y-box and CA repeat, but is lost on the further addition of a nondescript stretch of DNA 48 bp in length. It may be considered that this DNA fragment confers a high basal activity to the construct; however, the important point to be emphasized is that the construct is no longer responsive to $\mathrm{UV}$ induction. The response is regained through addition of the distal half of the promoter, containing three additional NF- $\kappa$ B motifs. The UV-responsive elements present in the TNF promoter bear no resemblance to UV-responsive sequences that have previously been defined (3).

Kruys et al. (8) previously observed that in transient and permanent transfections, a minimal TNF promoter, only 109 bp in length, was constitutively expressed in NIH 3T3 cells. By contrast, little or no basal expression of CAT activity was observed in the present transient transfection studies with promoters that were $<403 \mathrm{bp}$ in length. This discrepancy may result from the fact that, in this study, the reporter constructs were excised from the vector before transfection, and, therefore, were unattached to any adjacent DNA sequences. It would appear that a certain length of DNA (as much as $261 \mathrm{bp}$ ) must be appended upstream from the minimal TNF promoter to permit basal expression of the reporter.

Just as LPS exerts its inducing effect at more than one biosynthetic level, UV light induces transcription and, additionally, seems to exert a posttranscriptional effect on TNF biosynthesis. This is evident from the fact that comparable amounts of TNF mRNA accumulate in $\mathrm{C} 3 \mathrm{H} / \mathrm{HeJ}$ macrophages treated with LPS or with UV light; however, only the latter stimulus leads to protein production (Figs. 8 and 9 ).

Despite the above-mentioned similarity, many differences between the response to LPS and the response to UV irradiation are immediately apparent. The UV signaling pathway does not require the participation of $N F-\kappa B$, as judged by the fact that mutation of all four sites within the promoter did not impair the response. This observation does not contradict the finding that NF- $\kappa$ B is activated by UV light ( 3 ), nor does it call the importance of NF- $\kappa \mathrm{B}$ in other systems into question.

The Lps mutation, which effectively blocks signals elicited by LPS, fails to impede signaling initiated by UV irradiation. While the product of the Lps gene is but one component of the LPS signaling apparatus, it may be said that this protein, at least, finds no function in the transduction of signals initiated by UV light.

Finally, while the LPS signaling pathway was extinguished in NIH 3T3 $\times$ RAW 264.7 hybrid cells, no effect on UV signaling was noted. This finding was not unexpected. It is to be anticipated that if both parental cell lines express components of the pathway, a hybrid cell line should do so as well. The genes encoding components of the LPS signaling pathway have yet to be identified. However, it is reasonable to suppose that the pathway is composed of specialized proteins, expressed in macrophages but not in NIH 3T3 cells. The extinction of the LPS signaling pathway in somatic cell hybrids reflects this fact. By contrast, the apparently ubiquitous nature of the UV signaling pathway (which was intact in all cell lines examined) seems to have prevented its extinction by somatic cell hybridization.

Each of these observations argues that the signaling pathways used by UV light and by LPS are very different from one another, yet none of our findings exclude the possibility that a certain degree of overlap may exist. Recently, it was reported 
that $\mathrm{C} 3 \mathrm{H} / \mathrm{HeJ}$ mice fail to respond normally to UV irradiation, insofar as UV light does not attenuate hapten-mediated contact hypersensitivity in these animals as it does in $\mathrm{C} 3 \mathrm{H} /$ HeN mice (22). It must be emphasized that these studies are, by their design, confined to an analysis of effects at the level of the TNF gene, and do not encompass all possible effects of the Lps mutation. In particular, we cannot assess cooperative effects occurring between cells, as might exist in experiments performed with intact animals. However, the results that we have reported exclude the existence of a single common pathway triggered by UV light and by LPS.

Whatever the nature of the UV-induced pathway leading to TNF gene activation, it appears, as already noted, to be represented in most cells. Inasmuch as most cells never encounter UV light, this finding may suggest that the pathway evolved to serve a separate function. It is possible that other stimuli use the same signaling mechanism to activate expression of the TNF gene; e.g., that certain drugs (23) or physical agents (24) known to induce TNF do so through the same fundamental mechanism as UV light. Perturbations of the UV signaling pathway might, therefore, be expected to have pathologic effects.

In this context, it is worth recalling that all members of the TNF family of cytokines (including TNF- $\alpha$, lymphotoxin- $\alpha$, and lymphotoxin- $\beta$ [25]) are encoded by MHC-linked genes. To date, no other cytokine genes have been found to be so linked. The MHC linkage of the TNF gene, as much as the proinflammatory character of TNF, has driven speculation as to the role played by TNF in various autoimmune diseases (26-30). The UV-responsive nature of the TNF gene would also seem consistent with a potential role in photosensitivity, as observed in certain MHC-linked autoimmune diseases, including SLE (31). In the future, it will be of interest to determine whether the TNF gene is abnormally UV responsive in human SLE, or in murine models of the disease in which an MHClinked gene is known to be etiologically important $(32,33)$.

\section{Acknowledgements}

This work was supported, in part, by a grant from the National Institutes of Health (5-P01 DK-42582) and by a grant from the Tobacco Research Council (59636).

\section{References}

1. Piguet, P. F., G. E. Grau, C. Hauser, and P. Vassalli. 1991. Tumor necrosis factor is a critical mediator in hapten-induced irritant and contact hypersensitivity reactions. J. Exp. Med. 173:673-679.

2. Büscher, M., H. J. Rahmsdorf, M. Litfin, M. Karin, and P. Herrlich. 1988. Activation of the c-fos gene by UV and phorbol ester: different signal transduction pathways converge to the same enhancer element. Oncogene. 3:301-311.

3. Stein, B., H. J. Rahmsdorf, A. Steffen, M. Litfin, and P. Herrlich. 1989. UV-induced DNA damage is an intermediate step in UV-induced expression of human immunodeficiency virus type 1 , collagenase, $c$-fos, and metallothionein. Mol. Cell. Biol. 9:5169-5181.

4. Morrey, J. D., S. M. Bourn, T. D. Bunch, M. K. Jackson, R. W. Sidwell, L. R. Barrows, R. A. Daynes, and C. A. Rosen. 1991. In vivo activation of human immunodeficiency virus type 1 long terminal repeat by UV type A (UV-A) light plus psoralen and UV-B light in the skin of transgenic mice. J. Virol. 65:50455051 .

5. Shakhov, A. N., M. A. Collart, P. Vassalli, S. A. Nedospasov, and C. V. Jongeneel. 1990. $\kappa$ B-type enhancers are involved in lipopolysaccharide- mediated transcriptional activation of the tumor necrosis factor $\alpha$ gene in primary macrophages. J. Exp. Med. 171:35-47.

6. Han, J., T. Brown, and B. Beutler. 1990. Endotoxin-responsive sequences control cachectin/tumor necrosis factor biosynthesis at the translational level. $J$. Exp. Med. 171:465-475.

7. Kock, A., T. Schwarz, R. Kirnbauer, A. Urbanski, P. Perry, J. C. Ansel, and T. A. Luger. 1990. Human keratinocytes are a source for tumor necrosis factor $\alpha$ : evidence for synthesis and release upon stimulation with endotoxin or ultraviolet light. J. Exp. Med. 172:1609-1614.

8. Kruys, V., P. Thompson, and B. Beutler. 1993. Extinction of the tumor necrosis factor locus, and of genes encoding the lipopolysaccharide signaling pathway. J. Exp. Med. 177:1383-1390.

9. Beutler, B., and T. Brown. 1991. A CAT reporter construct allows ultrasensitive estimation of TNF synthesis, and suggests that the TNF gene has been silenced in non-macrophage cell lines. J. Clin. Invest. 87:1336-1344.

10. Han, J., G. Huez, and B. Beutler. 1991. Interactive effects of the TNF promoter and 3'-untranslated regions. J. Immunol. 146:1843-1848.

11. Shakhov, A. N., R. L. Turetskaya, D. V. Kuprash, S. A. Nedospasov, M. A. Collart, C. Drouet, and C. V. Jongeneel. 1990. Sequences involved in the regulation of TNF gene expression. In Molecular and Cellular Biology of Cytokines. Wiley-Liss, Inc., New York. 25-30.

12. Giroir, B. P., T. Brown, and B. Beutler. 1992. Constitutive synthesis of tumor necrosis factor in the thymus. Proc. Natl. Acad. Sci. USA. 89:4864-4868.

13. Giroir, B. P., K. Peppel, M. Silva, and B. Beutler. 1992. The biosynthesis of tumor necrosis factor during pregnancy: studies with a CAT reporter transgene and TNF inhibitors. Eur. Cytokine Network. 3:533-538.

14. Chen, C., and H. Okayama. 1987. High-efficiency transformation of mammalian cells by plasmid DNA. Mol. Cell. Biol. 7:2745-2752.

15. Gorman, C. M., L. F. Moffat, and B. H. Howard. 1982. Recombinant genomes which express chloramphenicol acetyltransferase in mammalian cells. Mol. Cell. Biol. 2:1044-1051.

16. Kawakami, M., and A. Cerami. 1981. Studies of endotoxin-induced decrease in lipoprotein lipase activity. J. Exp. Med. 154:631-639.

17. Favaloro, J., R. Treisman, and R. Kamen. 1980. Transcription maps of polyoma virus-specific RNA: analysis by two-dimensional nuclease S1 gel mapping. Methods Enzymol. 65:718.

18. Sambrook, J., E. F. Fritsch, and T. Maniatis. 1989. Molecular Cloning: A Laboratory Manual. Cold Spring Harbor Laboratory, Cold Spring Harbor, NY. 19. Caput, D., B. Beutler, K. Hartog, S. Brown-Shimer, and A. Cerami. 1986. Identification of a common nucleotide sequence in the 3'-untranslated region of mRNA molecules specifying inflammatory mediators. Proc. Natl. Acad. Sci. USA. 83:1670-1674.

20. Cseh, K., and B. Beutler. 1989. Alternative cleavage of the cachectin/TNF propeptide results in a larger, inactive form of secreted protein. J. Biol. Chem. 264:16256-16260.

21. Piguet, P. F. 1992. Keratinocyte-derived tumor necrosis factor and the physiopathology of the skin. Springer Semin. Immunopath. 13:345-354.

22. Yoshikawa, T., and J. W. Streilein. 1990. Genetic basis of the effects of ultraviolet light $B$ on cutaneous immunity. Evidence that polymorphism at the TnFa and Lps loci governs susceptibility. Immunogenetics. 32:398-405.

23. Chia, J. K. S., and E. J. McManus. 1990. In vitro tumor necrosis factor induction assay for analysis of febrile toxicity associated with amphotericin B preparations. Antimicrob. Agents Chemother. 34:906-908.

24. Sherman, M. L., R. Datta, D. E. Hallahan, R. R. Wechselbaum, and D. W. Kufe. 1991. Regulation of tumor necrosis factor gene expression by ionizing radiation in human myeloid leukemia cells and peripheral blood monocytes. J. Clin. Invest. 87:1794-1997.

25. Browning, J. L., A. Ngam-ek, P. Lawton, J. DeMarinis, R. Tizard, E. P. Chow, C. Hesslon, B. O'Brine-Greco, S. F. Foley, and C. F. Ware. 1993. Lymphotoxin $\beta$, a novel member of the TNF family that forms a heteromeric complex with lymphotoxin on the cell surface. Cell. 72:847-856.

26. Jacob, C. O., and H. O. McDevitt. 1988. Tumour necrosis factor-alpha in murine autoimmune 'lupus' nephritis. Nature (Lond.). 331:356-358.

27. Satoh, J., H. Seino, T. Abo, S. Tanaka, S. Shintani, S. Ohta, K. Tamura, T. Sawai, T. Nobunaga, T. Oteki, K. Kumagai, and T. Toyota. 1989. Recombinant human tumor necrosis factor $\alpha$ suppresses autoimmune diabetes in nonobese diabetic mice. J. Clin. Invest. 84:1345-1348.

28. Jacob, C. O., S. Aiso, S. A. Michie, H. O. McDevitt, and H. Acha-Orbea. 1990. Prevention of diabetes in nonobese diabetes mice by tumor necrosis factor (TNF): similarities between TNF-alpha and interleukin 1. Proc. Natl. Acad. Sci. USA. 87:968-972.

29. Held, W., H. R. MacDonald, I. L. Weissman, M. W. Hess, and C. Mueller. 1990. Genes encoding tumor necrosis factor $\alpha$ and granzyme $\mathrm{A}$ are expressed during development of autoimmune diabetes. Proc. Natl. Acad. Sci. USA. 87:2239-2243.

30. Jacob, C. O., Z. Fronek, G. D. Lewis, M. Koo, J. A. Hansen, and H. O. McDevitt. 1990. Heritable major histocompatibility complex class II-associated differences in production of tumor necrosis factor $\alpha$ : relevance to genetic predisposition to systemic lupus erythematosus. Proc. Natl. Acad. Sci. USA. 87:12331237.

31. Reinertsen, J. L., J. H. Klippel, A. H. Johnson, A. D. Steinberg, J. L. Decker, and D. L. Mann. 1978. B-lymphocyte alloantigens associated with systemic lupus erythematosus. N. Engl. J. Med. 299:515-518.

32. Knight, J. G., and D. D. Adams. 1978. Three genes for lupus nephritis in NZB $\times$ NZW mice. J. Exp. Med. 147:1653-1660.

33. Kotzin, B. L., and E. Palmer. 1987. The contribution of NZW genes to lupus-like disease in $(\mathrm{NZB} \times \mathrm{NZW}) \mathrm{F}_{1}$ mice. J. Exp. Med. 165:1237-1251. 